\title{
Spread of COVID-19 Pandemic in Zambia: A Mathematical Model
}

\author{
Eddie M. Mulenga ${ }^{1 *}$
}

${ }^{1} \mathrm{PhD}$ Candidate, School of Doctoral Studies, University of Valladolid, SPAIN

*Corresponding Author: eddiecaliber@gmail.com

Citation: Mulenga, E. M. (2020). Spread of COVID-19 Pandemic in Zambia: A Mathematical Model. Aquademia, 4(1), ep20xx. https://doi.org/10.29333/aquademia/8375

ARTICLE INFO

Received: 13 May 2020

Accepted: 20 Jun. 2020

\begin{abstract}
There has been a cumulative increase in the number of COVID-19 confirmed cases, recoveries as well as deaths in Zambia as declared by the Ministry of Health on regular basis. Based on the available statistical information, this article will discuss a mathematical model concerning the spread of COVID-19 in Zambia. To predict the spread of COVID-19 in Zambian provinces, a multiple regression analysis describing the inter-play of factors influencing the increase in the number of cases is used to formalize the relationship. To ascertain the accuracy of the mathematical model used, exponential graphs regarding the spread of coronavirus (COVID-19) since its arrival over time in Zambia were obtained.
\end{abstract}

Keywords: COVID-19, Mathematical model, predictor variables, regression model, infection rate, fatality rate, susceptible population

\section{INTRODUCTION}

On Wednesday, $18^{\text {th }}$ of March 2020, Zambia confirmed its first two cases of the novel coronavirus (Covid-19). Until 11 $1^{\text {th }}$ May 2020, the number of COVID-19 confirmed cases increased to 267 with 117 recoveries but sadly the number of deaths due to COVID-19 increased to 7 . The virus, which has progressed in a highly deadly manner especially in the United States of America, United Kingdom and Italy and caused massive deaths globally - is continuing to spread (Cakir \& Savas, 2020; Shrivastava \& Shrivastava, 2020; Basilaia \& Kvavadze, 2020; Koltsova et al., 2020). The rate at which this infection is spreading worldwide is alarming. Therefore, in this article the author has formulated a simple mathematical model to account for the increase in the number of COVID-19 cases in Zambia. This is consistent with other researchers worldwide (e.g. see Amanso et al., 2020; Donsimoni et al., 2020; Koltsova et al., 2020; Lucero, 2020; Roy \& Roy Bhattacharya, 2020; Sugiyanto \& Abrori, 2020) who have also constructed different models according to different parameters in relation to their countries. For example, Italy has seen a sharp increase in the number of new infections and deaths since the first case was recorded and as such researchers' close investigations and mathematical modeling may help political pioneers and health care systems to apportion enough resources, including work force, beds, and concentrated intensive care units, to deal with the circumstance in the following difficulty days and weeks (Lazzerini \& Putoto, 2020; Remuzzi \& Remuzzi, 2020).
Currently, the whole world has more questions than answers (e.g see Jiang, 2020; Tian et al., 2020) regarding the spread of the pandemic and in order to find solutions to the daily increasing questions, researchers across different fields are busy in research institutes and laboratories carrying out scientific experiments to provide global solutions. These fields progressively incorporate quantitative techniques, practical, inferential and -predictive models- uniting statistical data analysis, displaying modeling impacts involving innovative methodological approaches (Castellano, Fortunato, \& Loreto, 2009; Helbing, 2010; Short, Brantingham, Bertozzi, \& Tita, 2010; Weidlich, 2000).

The advancement of mathematical models with regards to modeling disease dynamics has a long history. Therefore, it is against this bacground that the focus of this paper is framed. Thus, the purpose of this study is to use the formutated mathematical model to predict coronavirus (COVID-19) outcomes.

\section{COVID-19 SPREADING AND RECENT FORECASTING}

Mathematical modeling in general has indeed come a long way in improving and also saving human life. Several scholars are busy worldwide trying to create predictive models to save human lives. Helbing et al. (2015) posits that models offer real life applications in addressing the spread of the diseases. It is argued that models and data of disease spreading create an 
opportunity to employ scientific knowledge to save human lives. Forecasting COVID-19 dissemination thus plays an important role to educate governments and the medical personnel on what is expected and which measures to force, and furthermore, to persuade the general public to hold fast to the measures that were forced to decelerate the spreading in case a deplorable situation arises (Baud et al., 2020; Crokidakis, 2020; McCloskey et al., 2020; Perc et al., 2020). On the other hand, financial experts are ascertaining and anticipating models which are sending stuns through the worldwide economy (Kraemer, Yang, Gutierrez, Wu, Klein, Pigott, \& Brownstein, 2020). In recent decades, the danger of pandemics has been significantly decreased by a further developed clinical framework, the advancement of modern anti-infection agents, antiviral medications, and vaccination crusades (Perc et al., 2020).

\section{MODEL CONSTRUCTION}

Based on the reviewed literature, for a region with a population $(P)$ (province, city), it is proposed that "the number of people who will die is directly proportional to the product of the numbers of those who could become infected, the number of people the virus is likely to kill and the rate at which the virus spreads. The mathematical model of this situation is given by equation (1) below:

$$
\begin{gathered}
N(\text { dead })=N(\text { Susceptible population }) \times \text { Infection rate } \\
\times \text { Fatality rate }
\end{gathered}
$$

where

Fatality rate $=\frac{\text { number of people who have died from the disease }}{\text { the number of people infected with the disease }}$ and infection rate is influenced by symptomaticity ratios.

In light of equation (1), any model prediction is dependent on two factors:

1. Data used and

2. Assumptions made

To construct a good predictive model on coronavirus (COVID-19) disease progression in Zambia, we need accurate data on (1) all the susceptible population in Zambia, (2) infection rate in each province, (3) fatality rate in each province and (4) disease progression rate in each province. Therefore, when a number of predictor variables $\left(x_{i}-\right.$ are the predictor variables) influence the outcome of the response single variable (y- response), multiple regression analysis can be used to formalize the relationship. That is;

$$
y=f\left(x_{1}, x_{2}, x_{3}, x_{4}, x_{5}, x_{6}, \ldots ., x_{n}\right)
$$

Thus, each part of the information in equation (1) above is dependent on a multiple of other factors given in equation (2) as predictor variables. For instance, the infection rate;

$$
y=f(\text { rate of infection })
$$

for every population of Zambia is going to be dependent on $x_{i}-$ factors (to mention a few):

$x_{1}$ : Total number of people tested (e.g. number of known cases)

$x_{2}$ : The kind of people tested (symptomatic or asymptomatic people as well) $x_{3}$ : Precision, accuracy and sensitivity of the test kits used

$x_{4}$ : Transmission rate (e.g how long the virus survives on surfaces, rate of spread by cough)

$x_{5}$ : Incubation period (e.g how symptoms are defined)

$x_{6}$ : Contract rate (e.g. location, isolation measures)

$x_{n}$

Similarly, for fatality rate (see eq. 4 ), we may have a number of factors such as:

$$
y=f(\text { rate of fatality) }
$$

$x_{1}$ : Treatment given to patients

$x_{2}$ : Hospital capacity (e.g. available stuff, ICU beds, ventilators etc)

$x_{3}$ : Number of known deaths (e.g. arising from number of known cases)

$x_{4}$ : Susceptible population (e.g. elevated risk factors such as age, comorbid conditions)

$x_{5}$ : Immunity (e.g. number of people recovered, vaccines used, etc)

$x_{6}$ : Number of people tested (e.g. symptomaticity ratio)

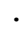

$x_{n}$

Therefore, to construct a model, we have to gather all the $x_{i}$ - predictor variables together, check for their certainty and uncertainty, how related (correlated) they are from each other, identify the relative importance of each predictor variable and finally establish whether a linear structure is the most appropriate form of relationship.

\section{RESULTS AND DISCUSSIONS}

According to current projections, the current total population of Zambia is estimated to be 18, 342, 224 as at June 2020. This number is used to gauge the coronavirus (COVID19) prompted death rate, infection rate and recovery rate per every 1000 population by utilizing suitable measurements of the illness relating to Zambia. The rate of infection is estimated to be 0.0593712 . This was calculated by dividing the total number of COVID- 19 cases as at $2^{\text {nd }}$ of June of 2020 by the total population multiplied by 1000 . This is consistent with (Amanso et al., 2020). From equation (1), It therefore, follows that the fatality rate is 0.006427 . Suppose, the susceptible population is 20000, we have;

$$
\begin{gathered}
N(\text { dead })=N\left(\begin{array}{c}
\text { Susceptible population }) \times \text { Infection rate } \\
\quad \times \text { Fatality rate }
\end{array}\right. \\
N(\text { dead })=20000 \times 0.0593712 \times 0.006427=7.63
\end{gathered}
$$

Results highlight that 7 people or more could die of COVID-19. This is not very surprising as 7 people have died so far from the time the first case was recorded in Zambia. It appears that the parameters (assumptions made) fit perfectly according to the current situation in Zambia. 
Zambia Coronavirus Cases May 2020 Data

Summary Download .

Zambia recorded 267 Coronavirus Cases since the epidemic began, according to the World Health Organization (WHO). In addition, Zambia reported 7 Coronavirus Deaths.

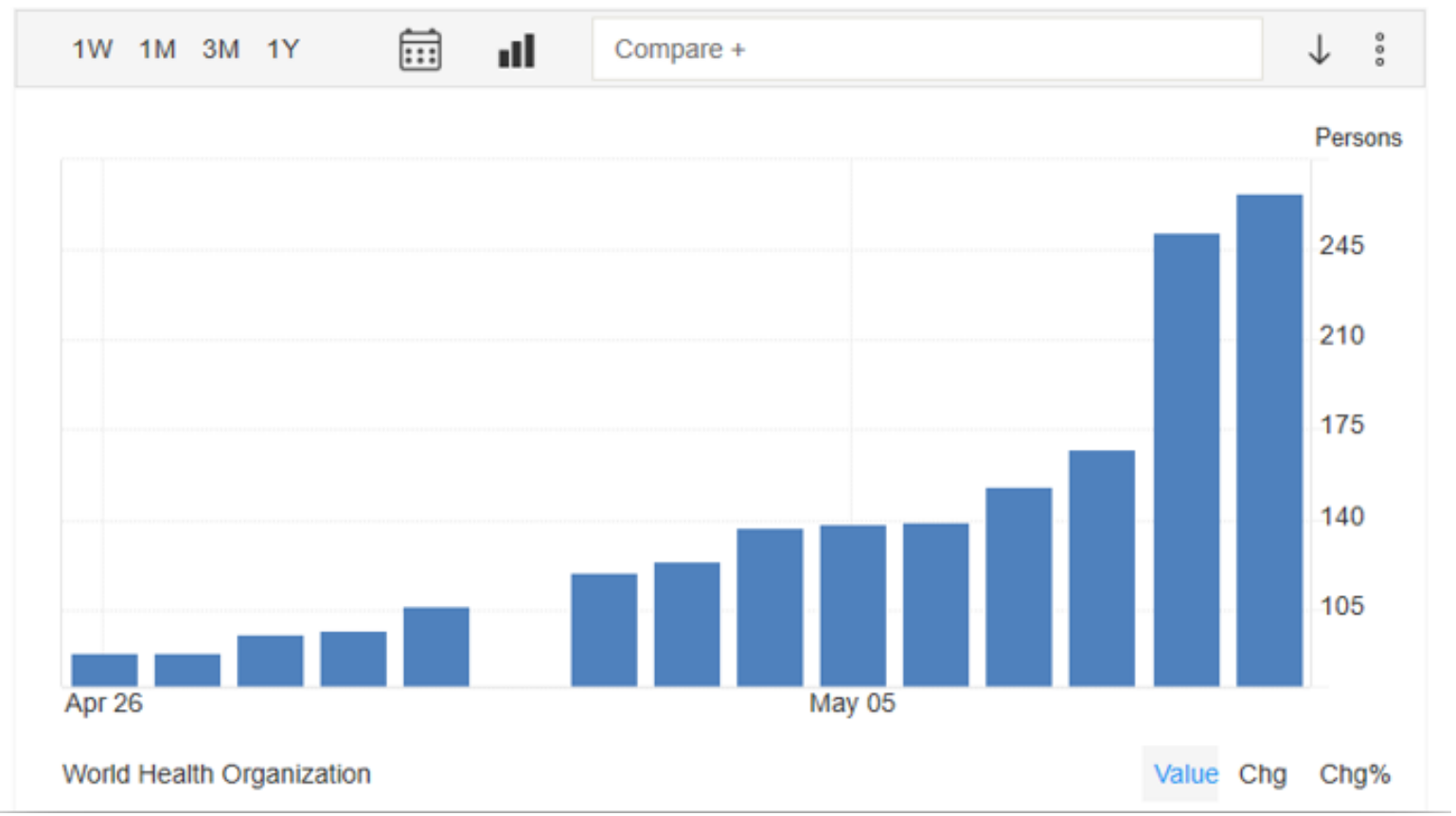

Figure 1. Exponential growth of COVID-19 cases by $11^{\text {th }}$ May, 2020

Next, in the event that the susceptible number of individuals who could become infected (susceptible population) is 10,000 , if the infection rate is $5 \%$ and the fatality rate is $2.5 \%$. Using the date $11^{\text {th }}$ May, 2020, let us examine Figure 1 where we may predict the total number of people who would die (approximate number of deaths) in a 30day future time interval ahead of us. Using equation (1), we have;

$$
\begin{aligned}
& N(\text { dead })=N(\text { Susceptible population }) \times \text { Infection rate } \\
& \times \text { Fatality rate } \\
& N(\text { dead })=10000 \times 5 \% \times 2.5 \%=12.5
\end{aligned}
$$

According to the results of the mathematical modelling of COVID-19 with the parameters used in this study, approximately, 13 people could die in a month on the off chance that adequate precautionary measures are not taken, or safeguards are decreased, the course of the pandemic may show an exceptionally quick alter in the negative sense (Amanso et al., 2020; Cakir \& Savas, 2020). Therefore, using the same parameters, this study predicts 65 deaths by the end of the year 2020. The trajectory of the pandemic will change and dramatically for the worse for the next 6 months especially if people ease up on wearing of face masks, handwashing, social distancing or relax with other precautions. To save lives, the estimated prediction of COVID-19 deaths assumes continued and uninterrupted vigilance by the general public, hospitals, health-care workers and government agencies.

Figure 1 shows that Zambia has seen an explosion of new COVID-19 cases on daily basis arising from mass testing done especially at the borders. For example, up until $1^{\text {st }}$ June 2020 , Zambia has conducted 3961 total tests in the last five days. Results disclosed that there has been a sporadic increase in the new cases. This surge in the new cases across the country is necessitated by lack of adherence to the public health guidelines such as avoiding unnecessary travels, maintaining proper hygiene and so on bringing the cumulative cases to 1089, 912 recoveries, 170 active cases, and 7 deaths. It is hoped that those who have recovered from this disease do not have underlying health conditions (Amanso et al., 2020).

Similarly, Figure 2 shows a spike rise in COVID-19 cases per month as provided by an increase in the number of infections. Moreover, the graph depicts that on $27^{\text {th }}$ April 2020, Zambia had recorded 89 confirmed cases with 3 deaths but the infection curve shows that there is over $50 \%$ increase of cases per day from $7^{\text {th }}$ May, 2020 until $11^{\text {th }}$ of May 2020 with 267 confirmed cases and 7 deaths. In just 15 days, the COVID-19 cases have risen from 89 to 267. Meanwhile, the rate of infections has also increased to 50 per day after 15 days. This explains the intensified measures and restrictions introduced by the government.

Different countries around the world collect data related to COVID-19 differently, and as such Zambia has her own inconsistencies in terms of data collection. For instance, Zambia has never conducted over 5000 tests in a day in any province while some other countries are giving tests to whoever wants one. Maybe this is due to the limited available test resources and medical stuff. This, however, affects how much citizens would know about the actual number of people 


\section{Coronavirus (COVID-19) spread over time}

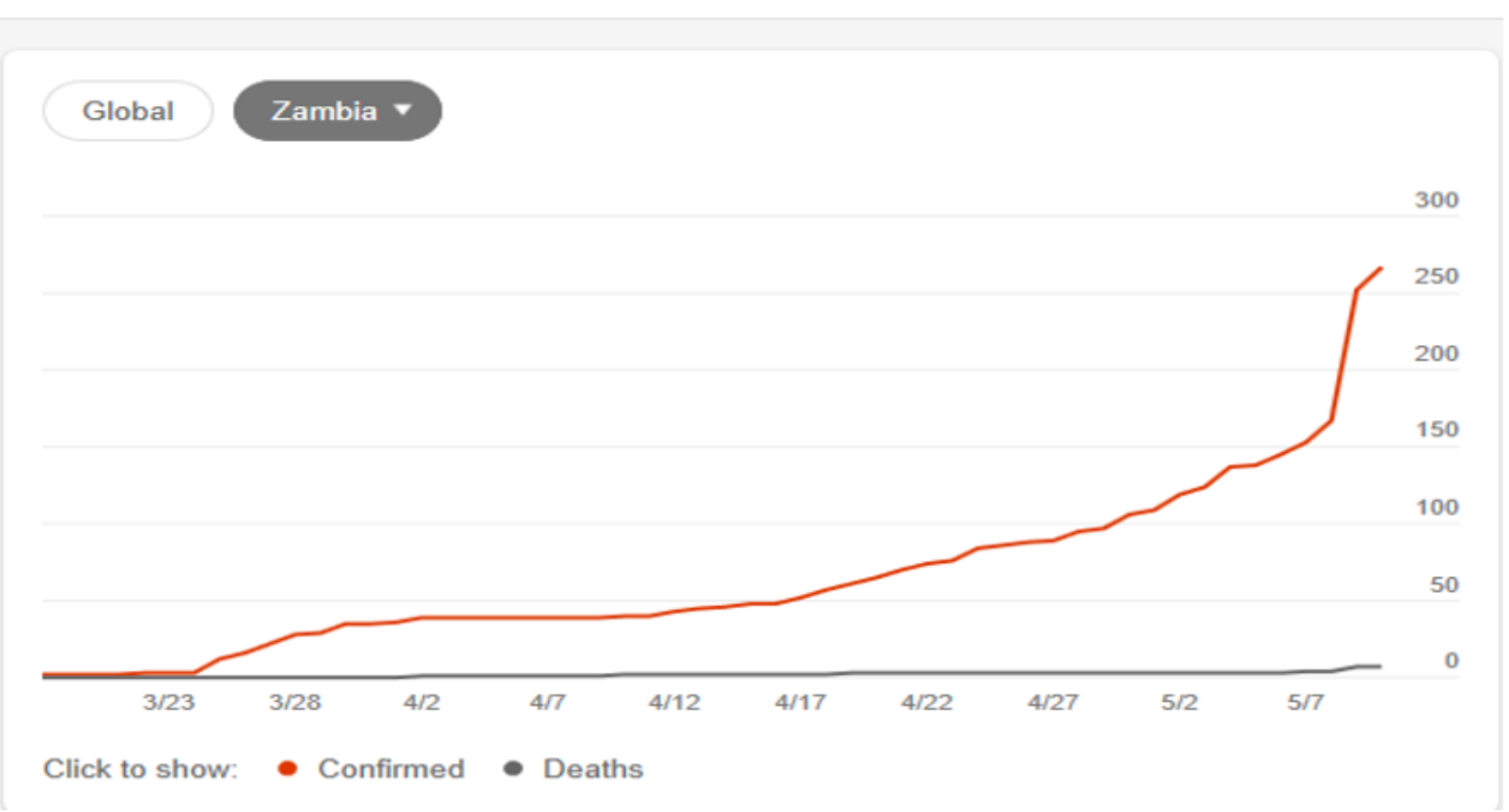

Figure 2. Spike in COVID-19 cases in Zambia

who have actually contracted COVID-19 against those who may have tested positive. Hence, some people who have never tested could be living with the infection and spreading it unknowingly, thereby killing a lot of people. The untested and unconfirmed infections could give rise to the rate of infection to the susceptible population as well as the rate of fatalities. This in turn affects the reported number of cases. This is why many Zambian citizens feel the Ministry of Health is underreporting the total number of people infected with the virus and deaths due to COVID-19.

\section{CONCLUSION}

To reduce the number of cumulative predicted deaths per province or city as well as the rapid spread of the virus, citizens need to adhere to all the health measures put up by the government such as - staying home, social distancing, wearing of face masks, hand washing, avoiding hand-shaking and maintaining highest levels of hygiene. This is a big step moving into the unknown that is likely to flatten the shape of the COVID-19 pandemic curve. However, these restrictions may differ by country, province or city. But the absence of these control measures may lead to increased infection rate, fatality rate and consequently high number of deaths due to COVID-19 as predicted by the model in this study. Additiotionally, multiple regression analysis was used in this study to quantify the influence of two or more predictor variables. The regression model has provided further insight into identifying the different kinds of relationships (factors) at play to predict the coronavirus outcomes. This has further highlighted that the inclusion of potentially useful predictor measures into the regression model such as sufficient access to ventilators, intensive care unit beds, adequate attendance by medical stuff, a lot of patients with even worse symptoms could survive the viral infenction and consequently avoid to be numbered on the overall national death toll.

\section{LIMITATIONS AND RECOMMENDATIONS}

However, the constructed model used in this study is limited to the data and assumptions made. It does not tell us anything about what happens to the individuals who have had the infection and recovered if they are immune to getting it once more, the susceptible population contracts-up until this point, the model did not consider post infection immunity with the virus. Finally, to reduce the spread of the virus and the number of people capable of dying from it, the author recommends that the Ministry of Health should use the constructed model in this study to understand the pattern of the infection rate, fatality rate and death rate considering all the predictor variables (factors) influencing the best response to COVID-19 outbreak. This is a big step in making informed decisions by the government of Zambia when responding to COVID-19 and living with this coronavirus (COVID-19) in the new normal.

\section{REFERENCES}

Amanso, O., Aguegboh, N., Achimugwu, P., Okeke, C., Chukwuemeka, B., Nnamaga, K., \& Oshilim, E. (2020). Mathematical model of the early incidence and spread of COVID-19 in Nigeria combined with control measure. International Journal of Scientific and Engineering Research, 11(4), 1110. 
Basilaia, G., \& Kvavadze, D. (2020). Transition to Online Education in Schools during a SARS-CoV-2 Coronavirus (COVID-19) Pandemic in Georgia. Pedagogical Research, 5(4), em0060. https://doi.org/10.29333/pr/7937

Baud, D., Qi, X., Nielsen-Saines, K., Musso, D., Pomar, L., \& Favre, G. (2020). Real estimates of mortality following COVID-19 infection. The Lancet Infectious Diseases, 20(July 2020), 773. https://doi.org/10.1016/S1473-3099(20)30195$\mathrm{X}$

Cakir, Z., \& Savas, H. B. (2020). A Mathematical Modelling Approach in the Spread of the Novel 2019 Coronavirus SARS-CoV-2 (COVID-19) Pandemic. Electronic Journal of General Medicine, 17(4), em205. https://doi.org/10.29333/ ejgm/7861

Castellano, C., Fortunato, S., \& Loreto, V. (2009). Statistical physics of social dynamics. Rev. Mod. Phys., 81(2), 591-646. https://doi.org/10.1103/RevModPhys.81.591

Crokidakis, N. (In Press). Modeling the early evolution of the COVID-19 in Brazil: results from a Susceptible-InfectiousQuarantined-Recovered (SIQR) model. International Journal of Modern Physics C. https://doi.org/10.1142/ S0129183120501351

Donsimoni, J. R., Glawion, R., Plachter, B., \& Wälde, K. (2020). Projecting the spread of COVID-19 for Germany. German Economic Review, 21(2), 181-216. https://doi.org/10.1515/ ger-2020-0031

Helbing, D. (2010). Quantitative Sociodynamics. Stochastic Methods and Models of Social Interaction Processes. Springer, Berlin. https://doi.org/10.1007/978-3-64211546-2

Helbing, D., Brockmann, D., Chadefaux, T., Donnay, K., Blanke, U., Woolley-Meza, O., Moussaid, M., Johansson, A., Krause, J., Schutte, S., \& Perc, M. (2015). Saving Human Lives: What Complexity Science and Information Systems can Contribute. Journal of Statistical Physics, 158(3), 735781. https://doi.org/10.1007/s10955-014-1024-9

Jiang, R. (2020). Inside China and COVID-19: Questions and answers. Travel Medicine and Infectious Disease, 34(MarchApril 2020), 101640. https://doi.org/10.1016/j.tmaid. 2020.101640

Kraemer, M. U., Yang, C. H., Gutierrez, B., Wu, C. H., Klein, B., Pigott, D. M., ... Brownstein, J. S. (2020). The effect of human mobility and control measures on the COVID-19 epidemic in China. Science, 368(6490), 493-497. https://doi.org/10.1126/science.abb4218
Koltsova, E., Kurkina, E., \& Vasetsky, A. (2020). Mathematical modeling of the spread of COVID-19 in Moscow. Computational Nanotechnology, 7, 99-105. https://doi.org/ 10.33693/2313-223X-2020-7-1-99-105

Lucero, J. (2020). Mathematical modeling of COVID-19 in Brazil. https://doi.org/10.13140/RG.2.2.25266.56004

McCloskey, B., Zumla, A., Ippolito, G., Blumberg, L., Arbon, P., Cicero, A., Endericks, T., Lim, P., \& Borodina, M. (2020). Mass gathering events and reducing further global spread of COVID-19: a political and public health dilemma. The Lancet, 395(April 4, 2020), 1096-1099. https://doi.org/ 10.1016/S0140-6736(20)30681-4

Perc, M., Miksić, N., Slavinec, M., \& Stozer, A. (2020). Forecasting COVID-19. Frontiers in Physics, 8, 127. https://doi.org/10.3389/fphy.2020.00127

Roy, S., \& Roy Bhattacharya, K. (2020). Spread of COVID-19 in India: A Mathematical Model. Journal of Science and Technology, 5(3), 41-47. https://doi.org/10.46243/ jst.2020.v5.i3.pp41-47

Short, M. B., Brantingham, P. J., Bertozzi, A. L., \& Tita, G. E. (2010). Dissipation and displacement of hotspots in reaction-diffusion models of crime. Proc. Natl. Acad. Sci. USA, 107(9), 3961-3965. https://doi.org/10.1073/ pnas.0910921107

Shrivastava, S., \& Shrivastava, P. (2020). Resorting to mathematical modelling approach to contain the coronavirus disease 2019 (COVID-19) outbreak. Journal of Acute Disease, 9(2), 49-50. https://doi.org/10.4103/22216189.281311

Sugiyanto, S., \& Abrori, M. (2020). A Mathematical Model of the Covid-19 Cases in Indonesia (Under and Without Lockdown Enforcement). Biology, Medicine, \& Natural Product Chemistry, 9(1), 15-19. https://doi.org/10.14421/ biomedich.2020.91.15-19

Tian, H., Liu, Y., Li, Y., Wu, C.-H., Chen, B., Kraemer, M., Li, B., Cai, J., Xu, B., Yang, Q., Wang, B., Yang, P., Cui, Y., Song, Y., Zheng, P., Wang, Q., Bjornstad, O., Yang, R., Grenfell, B., \& Dye, C. (2020). An investigation of transmission control measures during the first 50 days of the COVID-19 epidemic in China. Science, 368(6491), eabb6105. https://doi.org/10.1126/science.abb6105

Weidlich, W. (2000). Sociodynamics: A Systematic Approach to Mathematical Modelling in the Social Sciences. Tyler and Francis, London. 